\title{
Satisfaction on Housing Quality in Mukim Bandar Johor Bahru and Mukim Plentong
}

\author{
YANG HAZIQAH MUSA, ADIBAH YUSUF* \\ Faculty of Social Sciences and Humanities, Universiti Malaysia Sarawak, 94300 Kota Samarahan, Sarawak, \\ Malaysia \\ *Corresponding author: yadibah@unimas.my
}

\begin{abstract}
Housing study is one of the vital subjects these days as a home is a part of every person. The significance of it is undeniable because it has become one of the necessities of human life. Studies have shown that housing adequacy is connected with the Quality of Life because everything starts at home. The preceding housing problems will reflect on the policy problems of local authorities and management. Some of the previous aftermaths on housing might affect the balance and sustainability of residents. A lot of issues about housing have been drawn to the media especially in Malaysia. Water supply crisis, flood issue, a technical issue like elevator problem, waste management, security, lack of facilities such as public transport are some of the examples. It is also affecting the satisfaction towards housing quality indirectly. This study investigates the satisfaction on housing quality in Mukim Bandar Johor Bahru and Mukim Plentong, Johor Bahru, Johor which cover a total of 696,500 people. A sample of 196 respondents is surveyed to identify the locals' satisfaction with their housing quality in three aspects which are the physical of house, infrastructure, and the environment by using Cochran's formula. Descriptive analysis is used to analyse the quantitative data obtained. The result depicts the majority of respondents $(74.0 \%)$ are satisfied with their housing condition overall. Despite identifying housing quality, this study also helps to identify the problems that the locals encountered which came out from the three highest rankings on common problems. They are drainage ditch, road damage or narrow, and roof damage.
\end{abstract}

Keywords: Environment, housing quality, infrastructure, physical of house, satisfaction level.

Copyright: This is an open access article distributed under the terms of the CC-BY-NC-SA (Creative Commons Attribution-NonCommercial-ShareAlike 4.0 International License) which permits unrestricted use, distribution, and reproduction in any medium, for non-commercial purposes, provided the original work of the author(s) is properly cited.

\section{INTRODUCTION}

\section{Background of Study}

Housing as an adequate shelter is very important in a person's life. According to Henilane (2016), special attention has been drawn to the concept of 'housing' in the economic literature. The term 'housing' is defined by the scholars as a commodity, as a tangible asset with a potential return, as a fixed asset regardless of whether it is owned or rented, and as a capital similar to a machine, if it is operated by a worker, but as a commodity, if it is not.

In conjunction with achieving the vision of Majlis Bandaraya Johor Bahru, which is 'to become a culturally and sustainable international city', various development projects are being planned, especially housing. Many housing projects are done to provide suitable settlements and also to cater to the local population. Housing has become more than just a place to stay, it also could be an asset especially for those who can afford more than one unit of the house.

Adeleye, Azeez \& Yusuff (2014) claims that an individual's perception of the environment is fundamental as it becomes the point of departure for any analysis of people and environment relations. Affordability, quality, demographic factors, public facilities, safety, and security are some of the aspects the potential buyer would consider when they want to buy a house. It is undeniable that those aspects will determine whether the property has a better demand in the market. Over the years, planners and designers have used several criteria to evaluate housing quality. According to Anderson and Weldemann (as cited in Adeleye et al., 2014) these include economic, physical, and social criteria. 
This study will be looking at three aspects. One of the major components of the quality of housing is the physical of the house. External structure, internal structure, and internal environment are things that can be indicators to measure the quality of a house. According to Statistics New Zealand (2015), the external structure includes structural integrity, weather-lightness, security, external materials, and insulation, while internal structure describes the water supply, sewage disposal, power supply, and other internal components. Lastly, the internal environment is related to adequate ventilation, adequate lighting, floor surfaces free from tripping hazards, indoor air quality, and moisture levels. Another aspect that we will be looking at in this study is the facilities provided. Public services such as schools, hospitals, post offices, public transport, and police station are vital to people's well-being. This is because the facilities are nearer to them especially if there is an emergency. Housing quality can also be evaluated by looking at the environment. This relates to the availability of sufficient space in the residence. The main measuring instrument to describe space problems is the overcrowding rate (Streimikiene, 2015). An appropriate space of a home is essential because it is the place where people have their privacy and pleasant time.

\section{Literature Review}

\section{Quality of Life}

Various thinkers in the fields of social policy, psychology, economics, health services, and medicine proposed varying definitions of a good Quality of Life (QoL) as their way to answer some of life's ultimate questions, meanings or aims. According to the World Health Organization (2014), QoL is defined as an individual's insight of one's life situation in the context of the culture and value systems in which they live and concerning their goals, expectations, standards, and concerns. It is a wide-ranging notion affected in a complex way by the person's physical health, psychological condition, personal beliefs, social relationships, in addition to and the person's relationship to his/her environment. Diener, Suh, Lucas, and Smith (as cited in Theofilou, 2013) describe QoL as how a person measures the 'goodness' of multiple aspects of one's life which include emotional reactions to a life event, disposition, sense of life fulfilment, and satisfaction and, satisfaction with work and personal and personal relationships. Therefore, QoL is extremely important to serve the health and well-being of a person.

A research conducted by Flanagan (1978) in defining the Quality of Life of Americans found that 15 factors were important or very important to their QoL and that their necessities and wants were well or very well met. The 15 factors highlighted in the research were as follows: material comforts; health and personal safety; relationships with your parents, brothers, sisters, and other relatives; having and raising children; close relationship with husband/wife/a person of the opposite sex; close friends; helping and encouraging others; participation in activities relating to the local and national government and public affairs; learning; understanding yourself; work; expressing yourself; socializing; reading, listening to music, or observing sports events or entertainment; and participation in active recreation. In this research, Flanagan (1978) also stipulated that the 'ideal' way to measure an individual's QoL is by evaluating the experiences of each individual. Only a significant or remarkable impact on the individual's QoL would be reported to make it practical to implement such an evaluation. People could suffer from all the defects that subjective ratings have because memories are flawed and selective where a current experience may distort the report.

In Malaysia, the quality of life is a measurement of growth and harmony. There are several indicators to portray the wellbeing of the community, such as income and distribution, environment, transport and communication, health, education, housing, environment, family life, social participation, and public safety (Abu Samah, Hassan, Jaafar, Mohd Jaafar \& Raja Ariffin, 2013). Meanwhile Abdullah, Ahmad Sarkawi, and Md. Dali (2017) reveals that Malaysian Wellbeing Indices have been evaluated and published through a few reports like The Malaysian Quality of Life Reports (MQLI, 1999-2011), The Malaysian Wellbeing Index (MWI, 2013), The MURNInet (1998), and the MURNInets (2011), and, last but not least, The Malaysian Family Wellbeing Index (MFWI, 2011). 


\section{Housing Quality}

Quality means the standard of something as measured against other things of a similar kind, the degree of excellence of something where we put certain standards to measure it. As housing is one of the essential needs of an individual, considering its quality is a necessary element to ensure people's health especially children's development. Based on the study by Baker, Mason, and Mallett (as cited in Aniza, Norfazilah \& Norhayati, 2018), accessibility to adequate housing has been proven crucial specifically for vulnerable populations like the indigenous communities, to elevate their physical and mental well-being.

In looking for the most significant aspects to represent the quality of houses that is preferable to everyone, past researchers would be considering three main factors, including the physical factors, the social factors, and economic factors (Anderson \& Weldemann as cited in Adeleye et al., 2014; Abdul Rahman, Salleh \& Omar, 2012). Each factor provides a broader range to express its characteristics as to meet the satisfaction of the homeowner. Generally, most findings depict that the perception or satisfaction of housing is influenced by the housing quality. Abdul Rahman et al. (2012) stipulate that physical factors have four categories namely dwelling unit, facilities and services, accessibility, and surrounding environment, while the social factors can be distinguished in terms of socio-demographic, social community, and place attachment. On the other hand, they also claim that the economic factors are related to the residents' socio-economic background.

Various relevant indicators could be selected to regulate the quality of a house. Streimikiene (2015) views that the indicators for housing quality dimension are the percentage of crowding rate, percentage of housing deprivation rate by the number of items, percentage share of the total population considering their dwelling as too dark, and percentage share of the population satisfied with housing quality. One of the components of housing quality is ventilation, which means that air circulation plays a massive role in assuring that everyone in the house breathes soothingly the fresh air without any problem. It enhances the mood in the house that the household members feel comfortable. The same goes for the lighting in the house as poor indoor lighting could adversely affect one's well-being. It is not just about lighting mood, but poor eyesight could be a problem if the house is always in a dark condition. As much as plants would, we humans also need natural light daily.

The crowding rate in a home is also a consideration of housing quality. This relates to the housing space deficit where an increase in family size would contribute to the overcrowding problem in the house. Every household needs a different house structure according to its life cycle, whereby each stage requires different needs and purposes. In Hashim and Yahaya (2001), there are four stages to meet the housing needs of the life cycle, the wit; couples without children level; basic family level: toddler; basic family level: teenagers; and adult and old level.

Hence, having the most suitable dwelling according to the family size brings out positive impacts especially for childhood development. The crowding rate is not just about the housing deficit for family size. It includes the personal or private space that is essential for each individual to rest, having 'me-time' without any disturbance because everyone owns the right to privacy. In addition, the physical space between neighbours could be related to the aspect of the physical environment, which is one of the objectives of this study.

Physical aspects for housing are the biggest concern that a person would be thinking about because this forecasts the probability of risk that might happen, for example, how long the electrical system would perform its consistency to deliver enough electric supply. People nowadays tend to consume more electricity, so this aspect is needed to be put into consideration. Physical aspects also include the external environment such as the location, the layout of the housing area, the provision and location of public facilities and infrastructure, sustainability aspects, social aspects, and as well as cost and value for money (Ali, 2018). Indeed, all these aspects discussed the need for balance to guarantee the well-being of an individual or family as a small but significant institution that starts from home.

\section{Perception and Satisfaction on Housing}

Perception is a belief or opinion, often held by many people and based on how things are viewed and perceived. Mathews and Parker (as cited in Al-KhanbashiRaja \& Mohit, 2014) state that satisfaction is a process of evaluation 
between what was received and what was expected. It is an evaluation to describe the degree of contentment of a person. Perception and satisfaction play important role in this study to reach the person's goal where both will be related to the dwelling.

Research has been conducted to determine the perception of housing in the Ogun State, southwest of Nigeria. For instance, Adeboye, Alagbe, and Ibem (2015) reveal that the respondents generally felt their housing conditions were not sufficient in meeting their current needs and expectation where, consequently, they were not contented or happy. Dwelling occupancy type and public social amenities (services) are both the first factor that accounted for $18.084 \%$ which is the highest of the variance, followed by the second factor, indoor environment quality, with $11.076 \%$ of the variance. As for the findings of the study, a strong relationship between housing adequacy and residential satisfaction is proven to the basic assumption. The research includes three dimensions of evaluating residential satisfaction, which are:

a) physical, social and economic environment oh housing estates

b) size, type location, appearance, and privacy of residence

c) security

As for housing satisfaction in Malaysia, Mohit and Mahfoud (2015) did a study on residential satisfaction in double-storey terrace housing in Kuala Lumpur. They examined five main components and 59 variables. The findings show that the residents are moderately dissatisfied with the neighbourhood and public facilities. On the other hand, they are a little over slightly satisfied with the physical features, housing support services, and the social environment. Overall, the correlation shows that satisfaction is highly related to housing support, social environment, and physical components rather than with the public and neighbourhood facilities components. Another study conducted by Ali and Mohit (2016) to determine the satisfaction and quality of urban life in Setiawangsa, Kuala Lumpur, shows that the respondents are very satisfied with their housing particularly in the aspects of home, neighbourhood, and quality of urban life. Even though cities are synonymous with hectic and stressful conditions, the study reveals that with an adequate place or environment to live in, people still could gain better welfare to achieve the true quality of life.

\section{METHODS}

\section{Location of Study}

This study was conducted in the range of two mukims which are Mukim Bandar Johor Bahru and Mukim Plentong. The two places are located spatially in the Johor Bahru District, Johor where the administrative center of the state is settled. Based on the data from Pusat Infrastruktur Data Geospatial Negara (2011), a sum of seven mukims are in Johor Bahru District which are Mukim Jelutong, Mukim Plentong, Mukim Sungai Tiram, Mukim Tanjung Kupang, Mukim Tebrau, Mukim Bandar Johor Bahru and Mukim Pulai as shown in Table 1. Both mukims are located adjacent to each other where the area of Mukim Bandar Johor Bahru is smaller than Mukim Plentong with the area of $41.1 \mathrm{~km}^{2}$ and $256 \mathrm{~km}^{2}$, respectively, according to the Department of Statistics Malaysia (2010). In comparison to the other five mukims, these two mukims are known as highly urbanised
Table 1. The total population according to mukim.

\begin{tabular}{lc}
\hline Mukim & Population \\
\hline Bandar Johor Bahru & 119,900 \\
Plentong & 576,600 \\
Jelutong & 27,200 \\
Pulai & 449,500 \\
Sungai Tiram & 17,500 \\
Tanjung Kupang & 12,400 \\
Tebrau & 397,200 \\
\hline Total & $\mathbf{1 , 6 0 0 , 3 0 0}$ \\
\hline
\end{tabular}


and where there is a higher density of population, and housing development is growing rapidly since the 1990 s. Figure 1 is the location of the study.

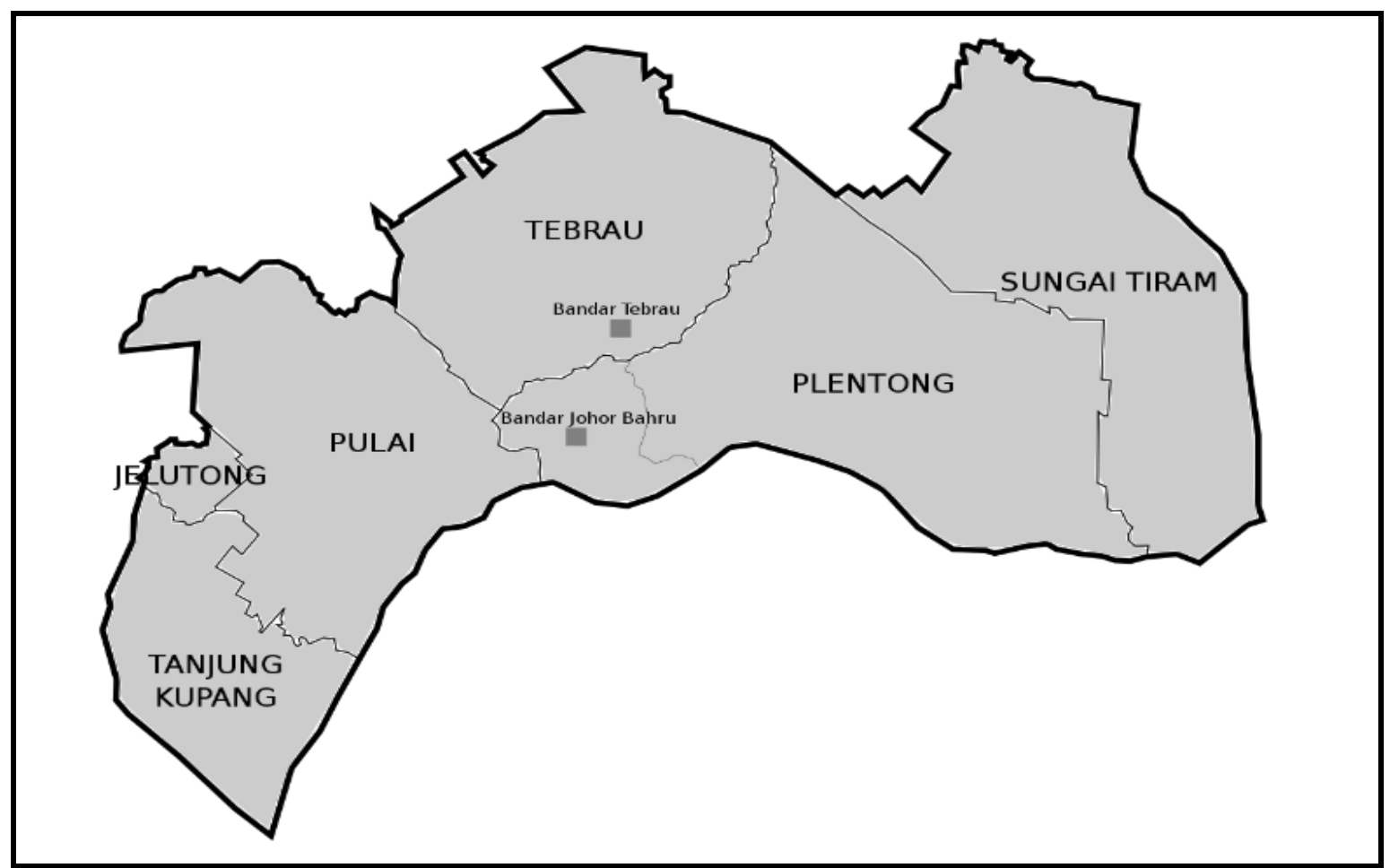

Figure 1. The location of Mukim Bandar Johor Bahru and Mukim Plentong. (Source: Pusat Infrastruktur Data Geospatial Negara, 2011)

\section{Data Collection}

The research instrument used in this study is self-administered questionnaires. Likert Scale was used to evaluate the satisfaction on the quality of the houses among the targeted respondents particularly from the aspects of physical, infrastructure, and environment. Purposive sampling was applied where the distinct criteria were the legitimate homeowner or tenant, the head of household, or representative, who is knowledgeable about the house condition and has been staying at the house.

Based on the information gathered from the Jabatan Perangkaan Malaysia Negeri Johor (N. Anis, personal communication, October 3, 2019), the total population of the two mukims chosen is 696,500 . Hence, this study used Cochran's formula to get the number of the sample because it is suitable for a large population. The sample size was 196. The respondents were chosen randomly from both mukims.

Cochran's formula is as follows,

$$
n_{o}=\frac{Z^{2} p q}{e^{2}}
$$

Where:

$e$ is the margin of error

$p$ is the estimated proportion of the population

$q$ is $1-\mathrm{p}$

$\mathrm{Z}$ - value is found in $\mathrm{Z}$ table 
As there is not much information on the subject, to begin with, this study assumes that half of the population are the homeowners where $\mathrm{p}=0.5$. $95 \%$ of confidence is implemented for precision gives us the Zvalue of 1.96 , with $7 \%$ precision. Therefore, the full calculation is:

$n_{o}=\frac{Z^{2} p q}{e^{2}}$

$n_{o}=\frac{(1.96)^{2}(0.5)(1-0.5)}{0.07^{2}}$

$n_{o}=196$

\section{Data Analysis}

Descriptive analysis was implemented to analyse the quantitative data collected from the survey. Statistical Package for Social Sciences (SPSS) was used as the software to record and interpret the data obtained. Through SPSS, the data collected can be simply coded to run.

\section{RESULTS}

The Likert Scale was used for determining the perception of housing satisfaction. Five types of evaluation terms were used which are $(1=$ Very not satisfied, $2=$ Not satisfied, $3=$ Not sure, $4=$ Satisfied, $5=$ Very satisfied). There were three main aspects of housing satisfaction variables that this study was focused. They were the physical of house, environment, and infrastructure. As shown in Table 2, most of the respondents were 'Satisfied' and 'Very Satisfied' for each variable with a total of more than $50 \%$. For the physical of house aspect, the parking area had the lowest total percentage of 'Satisfied' (41.8\%) and 'Very Satisfied' (26.0\%) among all the variables. Meanwhile, the infrastructure aspect had the lowest total percentage of both 'Satisfied' and 'Very Satisfied' too, particularly on public transport facilities (55.1\%), adequacy of safety (49.4\%), and adequacy of recreational facilities (55.1\%). On contrary, home cleanliness $(87.2 \%)$ and housing location $(81.1 \%)$ were the variables that had the highest total percentage of both 'Satisfied' and 'Very Satisfied' in the aspect of the environment.

As Table 3 below, the highest mean was the physical of house aspect with 4.0. This depicted that people were mostly satisfied with the physical of the house overall. On contrary, the lowest mean was 3.7 for the environmental aspect. Both infrastructure and environment were in 'Not Sure' because the mean was below 4.0.

Table 4 showed the comparison means for two mukims. Mukim Johor Bahru had a higher mean for the physical of the house (4.0) and environment aspects (3.9). While the infrastructure aspect in Mukim Johor Bahru was slightly lower with 3.8 compared to 3.9 in Mukim Plentong. Both the physical of house (3.9) and environment (3.6) aspects in Mukim Plentong were lower than Mukim Johor Bahru.

Table 5 depicted the overall satisfaction with housing quality. 145 respondents from 196 chose 'Yes' with the biggest percentage of $74.0 \%, 10.2 \%$ were from respondents who chose 'Moderate' and the smallest percentage was $2.6 \%$ who answered 'No'. This section was an open-ended question which was why some respondents skipped answering this part, with the irrelevant number of 26 respondents.

Table 6 indicated the common housing problems encountered by the homeowner. They ranked the issues from 1 to 12 in a close-ended question. Rank 1 was indicating the most common housing problem while Rank 12 was the least likely common housing problem. The drainage ditch was the highest rank as many respondents put it as Rank 1. The outcomes were shown as in Table 6. 
Table 2. Perception on housing satisfaction in percentage.

\begin{tabular}{|c|c|c|c|c|c|c|}
\hline & \multirow{2}{*}{ Housing satisfaction variables } & \multicolumn{5}{|c|}{ Evaluation terms (\%) } \\
\hline & & Very Not satisfied & Not Satisfied & Not Sure & Satisfied & Very Satisfied \\
\hline \multicolumn{7}{|c|}{ Physical of house } \\
\hline 1. & Wall structure & 1.0 & 8.7 & 12.8 & 52.0 & 25.5 \\
\hline 2. & Floor structure & 0.0 & 7.7 & 11.2 & 53.6 & 27.6 \\
\hline 3. & Roof structure & 1.5 & 2.6 & 20.4 & 46.9 & 21.9 \\
\hline 4. & Piling structure & 0.5 & 4.6 & 14.3 & 55.6 & 25.0 \\
\hline 5. & Source of water supply & 1.0 & 4.6 & 11.7 & 52.6 & 30.1 \\
\hline 6. & Source of electricity supply & 1.0 & 2.0 & 9.7 & 53.6 & 33.7 \\
\hline 7. & Condition of toilet & 0.5 & 10.2 & 13.3 & 52.0 & 24.0 \\
\hline 8. & Condition of bedroom & 0.0 & 4.1 & 12.2 & 56.6 & 27.0 \\
\hline 9. & Condition of kitchen & 1.0 & 10.0 & 13.8 & 49.5 & 26.0 \\
\hline 10. & Condition of dining room & 3.6 & 4.6 & 15.8 & 49.5 & 26.5 \\
\hline 11. & Condition of living room & 1.5 & 3.1 & 9.7 & 53.1 & 32.7 \\
\hline 12. & Number of bathrooms & 3.1 & 11.7 & 9.2 & 47.4 & 28.6 \\
\hline 13. & Number of bedrooms & 1.5 & 4.6 & 16.8 & 49.5 & 27.6 \\
\hline 14. & Number of sockets & 1.5 & 8.7 & 13.8 & 43.9 & 32.1 \\
\hline 15. & Door/gate structure & 1.5 & 7.1 & 15.3 & 51.5 & 24.5 \\
\hline 16. & Window structure & 2.6 & 6.1 & 11.7 & 55.6 & 24.0 \\
\hline 17. & Home area & 2.6 & 5.6 & 36.2 & 51.0 & 30.1 \\
\hline 18. & Home design & 1.0 & 5.1 & 16.3 & 51.0 & 26.5 \\
\hline 19. & Parking area & 4.6 & 9.7 & 17.9 & 41.8 & 26.0 \\
\hline \multicolumn{7}{|c|}{ Infrastructure } \\
\hline 1. & Public transport facilities & 6.6 & 12.8 & 25.5 & 40.8 & 14.3 \\
\hline 2. & Adequacy of waste management & 4.6 & 4.1 & 17.9 & 50.0 & 23.5 \\
\hline 3. & Adequacy of good schools & 1.0 & 3.6 & 13.8 & 48.0 & 33.7 \\
\hline 4. & Adequacy of shopping facilities & 1.5 & 2.0 & 13.3 & 40.3 & 42.9 \\
\hline 5. & Adequacy of roads & 2.0 & 3.6 & 11.2 & 49.5 & 33.7 \\
\hline 6. & Adequacy of streetlights & 1.0 & 2.6 & 13.3 & 48.0 & 35.2 \\
\hline 7. & Adequacy of the place of worship & 4.1 & 1.5 & 7.7 & 47.4 & 39.3 \\
\hline 8. & Adequacy of safety & 9.2 & 15.3 & 26.0 & 32.1 & 17.3 \\
\hline 9. & Adequacy of recreational facilities & 6.1 & 13.8 & 25.0 & 32.1 & 23.0 \\
\hline
\end{tabular}


Table 2. Cont. .

\begin{tabular}{|c|c|c|c|c|c|c|}
\hline & \multirow{2}{*}{ Housing satisfaction variables } & \multicolumn{5}{|c|}{ Evaluation terms (\%) } \\
\hline & & Very Not satisfied & Not Satisfied & Not Sure & Satisfied & Very Satisfied \\
\hline \multicolumn{7}{|c|}{ Environment } \\
\hline 1. & Privacy level & 3.1 & 12.2 & 19.4 & 42.9 & 22.4 \\
\hline 2. & Presence of foul odour & 7.1 & 15.8 & 29.4 & 41.8 & 14.8 \\
\hline 3. & Noise level & 7.1 & 15.3 & 15.8 & 45.9 & 15.8 \\
\hline 4. & Crime rate & 4.6 & 15.3 & 25.5 & 40.8 & 13.8 \\
\hline 5. & Housing location & 3.1 & 4.6 & 11.2 & 51.0 & 30.1 \\
\hline 6. & Safety & 5.6 & 11.2 & 15.8 & 51.0 & 16.3 \\
\hline 7. & Congestion rate & 4.1 & 15.3 & 15.8 & 49.0 & 15.8 \\
\hline 8. & Environmental problem & 4.9 & 12.8 & 20.4 & 43.9 & 18.4 \\
\hline 9. & Local community & 2.6 & 5.1 & 15.3 & 53.1 & 24.0 \\
\hline 10. & Air ventilation & 3.1 & 7.1 & 11.2 & 52.0 & 26.5 \\
\hline 11. & Home cleanliness & 1.5 & 2.0 & 9.2 & 55.1 & 32.1 \\
\hline 12. & Temperature comfort & 2.0 & 6.6 & 12.2 & 52.6 & 26.5 \\
\hline
\end{tabular}

Table 3. Descriptive statistics for housing satisfaction variables.

\begin{tabular}{lcccc}
\hline & N & Minimum & Maximum & Mean \\
\hline Physical of house & 19 & 3.8 & 4.2 & 4.0 \\
Infrastructure & 9 & 3.3 & 4.2 & 3.9 \\
Environment & 12 & 3.4 & 4.1 & 3.7 \\
\hline
\end{tabular}

Table 4. Descriptive statistics for housing variables according to two mukims.

\begin{tabular}{lcccc}
\hline & N & Minimum & Maximum & Mean \\
\hline Mukim Johor Bahru & & & & \\
\hline Physical of house & 19 & 3.7 & 4.2 & 4.0 \\
Infrastructure & 9 & 3.3 & 4.3 & 3.8 \\
Environment & 12 & 3.6 & 4.2 & 3.9 \\
\hline Mukim Plentong & & & & \\
\hline Physical of house & 19 & 3.7 & 4.1 & 3.9 \\
Infrastructure & 9 & 3.3 & 4.3 & 3.9 \\
Environment & 12 & 3.2 & 4.1 & 3.6 \\
\hline
\end{tabular}


Table 5. Overall satisfaction on housing quality.

\begin{tabular}{lrcccc}
\hline & & Frequency & Percent & Valid Percent & Cumulative Percent \\
\hline Valid & Yes & 145 & 74.0 & 85.3 & 85.3 \\
& Moderate & 20 & 10.2 & 11.8 & 97.1 \\
& No & 5 & 2.6 & 2.9 & 100.0 \\
& Total & 170 & 86.7 & 100.0 & \\
\hline \multirow{2}{*}{ Missing } & Irrelevant & 26 & 13.3 & & \\
\hline Total & 196 & 100.0 & & & \\
\hline
\end{tabular}

\section{DISCUSSION}

Overall, across the variables to evaluate the satisfaction in housing quality, this research found that the majority of the respondents are satisfied with their housing quality which includes the physical of the house, environment, and infrastructure. Hence, this indirectly answered the first objective of the research which is to identify the perception of the quality of housing from the three perspectives mentioned before. They are not dealing with any big issues that threaten their life, safety, or health. Among the three main aspects, respondents are more satisfied with the physical of the house. The other two aspects frequently depend on responsible agencies such as Jabatan Kerja Raya and Majlis Bandaraya. Any problem encountered cannot be solved directly, unlike the physical of house. Thus, there is no big issue on the physical of the houses that would contribute to dissatisfaction.

Based on the survey conducted, some respondents faced a little unpleasant satisfaction on the parking area for physical structure. They complained that the number of parking spaces is insufficient and sometimes their car is blocked by another car. As for the infrastructure aspect, public transport facilities, adequacy of both safety and recreational facilities have less satisfaction among the respondents. On another note, all sub-variables in the environment are chosen as satisfied mostly by the respondents. A foul odour and noise level have the highest percentage of 'Very Not Satisfied', which means that some of the respondents suffered from these issues. It is believed that this is due to the housing location. Some of the respondents live in an industrial location at Pasir Gudang (in Mukim Pletong) which affects the level of satisfaction of the variables. However, the majority of respondents chose 'Satisfied' for overall satisfaction on housing quality with a percentage of $74.0 \%$.
Table 6. Common housing problems encountered.

\begin{tabular}{lc}
\hline Problems Encountered & Rank \\
\hline Drainage ditch & 1 \\
Road damage/narrow & 2 \\
Roof damage & 3 \\
Electrical wiring & 4 \\
Lighting & 5 \\
Piping & 6 \\
Vandalism & 7 \\
Disruption of water supply & 8 \\
Disruption of electrical supply & 9 \\
Air ventilation & 10 \\
Crime & 11 \\
Neighbourhood problem & 12 \\
&
\end{tabular}


Various housing issues have been determined by the respondents in this research. They ranked the issues from the most common to the least problems, where the issue would be in the first rank if the percentage of respondents has the highest number. Therefore, this covered the second objective of the research which to identify the challenges in housing. The most frequent issues that people ranked the highest are the drainage ditch, road damage or narrowed road, and roof damage. Electrical wiring is in the fourth-ranked despite most respondents are satisfied with the physical of house because the house is built since the 1990s. The houses have been ages and have inappropriate wiring plan. Meanwhile, road damages or narrow roads are ranked second and it is believed due to the homeowners had a few cars that they park outside of their house. This causes the narrow road. In some cases, the road itself is built narrow especially those houses in the 1990s and before. Other issues are also significant as the common issues because these challenges actually will physically or emotionally disrupt the daily life of respondents. Hence, there is a need to overcome these issues.

\section{CONCLUSION}

Determining the way that could enhance the quality of life in terms of homeownership plays an important role to secure any social impact especially when it comes to inner peace or mental illness. A home is a place to feel secure and safe where homeownership, therefore, acts as an important role in mitigating life stress, especially in old age (Szabo, Allen, Alpass \& Stephens, 2017). At least people should discover their bare minimum to tolerate the housing quality. The healthiness of people's minds should be the priority regarding any situation.

The variables used in this study, which is to determine the perception of housing quality, should be more varied for further research. By this, more details can be gathered to improvise the findings of this type of research. Broad information will help in identifying what is the best solution to overcome any consequences particularly because different dimension tells different layers of the issue. As for this research, only three main perspectives are covered which are the physical of the house, environment, and infrastructure, ascribing the simpler to determine housing satisfaction. Not just that, more sub-variables also need to be put in appropriate consideration to get the best result.

The responsible agency such as Majlis Bandaraya Johor Bahru and Jabatan Kerja should take note of the common problems that the respondents encountered especially the drainage ditch, road damages or narrow roads, and roof damages. These problems could lead to a more serious problem. Refining the quality standard or enhancing law is very preferable to overcome the issues.

\section{ACKNOWLEDGEMENTS}

This research is a result of less than one year of work with different hurdles that have been crossed, during which several people have been involved and played a big role in its completion. I would like to extend my deepest sincere gratitude to everyone who participated in this study whether directly or indirectly, especially to the respondents, Melati Ehsan Development Sdn. Bhd., SP Setia Berhad, and UNIMAS. Your contributions helped a lot to complete this research and I am so grateful for that.

\section{REFERENCES}

Abdullah, A., Ahmad Sarkawi, A., \& Md. Dali, N. (2017). An analytical study of Malaysia's quality of life indicators. Journal of Business and Economics, 8(6), 488-498.

Abdul Rahman, N., Salleh, A. G., \& Omar, D. (2012). Determinant factors of neighbourhood quality. Journal of the Malaysian Institute of Planners, 10, 1-16.

Abu Samah, A., Hassan, N., Jaafar, M. N., Mohd Jaafar, N. I., \& Raja Ariffin, R. N. (2013). Perception on quality of life in Malaysia: The urban-rural divide. Journal of the Malaysian Institute of Planners, 14, 21-40.

Adeboye, A. B., Alagbe, O. A., \& Ibem, E. O. (2015). Similarities and differences in residents' perception of housing adequacy and residential satisfaction. Journal of Building Performance, 16(1), 1-14.

Adeleye, O. A., Azeez, T. O., \& Yusuff, I. O. (2014). Perception of housing quality by residents and non-residents of Ibara housing estate, Abeokuta, Ogun State, Nigeria. American Journal of Human Ecology, 3(3), 35-42.

Al-KhanbashiRaja, A. M. M., \& Mohit, M. A. (2014). Residential satisfaction - concept, theories and empirical studies. Journal of the Malaysian Institute of Planners, 3, 47-66. 
Ali, M. (2018). Interpreting the meaning of housing quality towards creating better residential environment. Environment-Behaviour Proceedings Journal, 3(8), 1-16.

Ali, M. S., \& Mohit, M. A. (2016). Neighbourhood satisfaction and QOUL in middle-income housing in Kuala Lumpur City, Malaysia. Journal of the Malaysian Institute of Planners, 14, 81-94.

Aniza, I., Norfazilah, A., \& Norhayati, M. (2018). Housing infrastructure and quality of life of orang asli and nonorang asli populations in Kuala Lumpur. Malaysia Journal of Public Health Medicine, 18(1), 28-37.

Department of Statistics Malaysia. (2010). Malaysia: Subdivision. Retrieved October 7, 2019 from https://www. citypopulation.de/en/malaysia/mukim/admin/

Flanagan, J. C. (1978). A research approach to improving our quality of life. American Psychologist, 138-147.

Hashim, A. H., \& Yahaya, N. (2001). Perumahan dan kediaman. Serdang: Penerbit Universiti Putera Malaysia.

Henilane, I. (2016). Housing concept and analysis of housing. Baltic Journal of Real Estate Economic and Construction Management, 4, 168-179.

Mohit, M. A., \& Mahfoud, A. A. (2015). Appraisal of residential satisfaction in double-storey terrace housing in Kuala Lumpur, Malaysia. Habitat International, 47, 286-293.

Pusat Infrastruktur Data Geospatial Negara. (2011). Kod dan nama sempadan pentadbiran tanah. Retrieved December 10, 2019 from http://www.mygeoportal.gov.my/ms/kod-dan-nama-sempadan-pentadbiran-tanahunique-parcel-identifier-upi

Statistics New Zealand (2015). Measuring housing quality: Potential ways to improve data collection on housing quality in New Zealand. Retrieved October 28, 2019 from http://archive.stats.govt.nz/browse for_stats/ people_and_communities/housing/measuring-housing-quality.aspx

Streimikiene, D. (2015). Quality of life and housing. International Journal of Information and Education Technology, 5(2), 140-145. Retrieved October 20, 2019, from http://www.ijiet.org/papers/491-S10009.pdf

Szabo, A., Allen, J., Alpass, F. \& Stephens, C. (2017). Loneliness, socio-economic status and quality of life in old age: the moderating role of housing tenure. Ageing and Society, 39(1), 998-1021. Retrieved November 12, 2019, from https://www.cambridge.org/core/journals/ageing-and-society/article/loneliness-socioeconomicstatus-and-quality-of-life-in-old-age-the-moderating-role-of-housing-tenure/305B07F0BA3EAB1DC827E 417DE61B14E

Theofilou, P. (2013). Quality of life: Definition and measurement. Europe's Journal of Psychology, 9(1), 150162.

World Health Organization. (2014). WHOQOL: Measuring Quality of life. Retrieved November 15, 2019 from https://www.who.int/healthinfo/survey/whoqol-qualityoflife/en/ 